\title{
Effect of miR-146a-5p on proliferation and metastasis of triple-negative breast cancer via regulation of SOX5
}

\author{
CHENGSHUAI SI, QIAO YU and YUFENG YAO \\ Department of General Surgery, Jiangsu Cancer Hospital, Jiangsu Institute of Cancer Research and \\ Nanjing Medical University Affiliated Cancer Hospital, Nanjing, Jiangsu 210009, P.R. China
}

Received July 6, 2017; Accepted October 25, 2017

DOI: $10.3892 /$ etm.2018.5945

\begin{abstract}
MicroRNA (miR)-146a-5p functions as a tumor suppressor in various types of cancer. However, the role of miR-146a-5p in the development of triple-negative breast cancer (TNBC) is unclear. The present study aimed to investigate the role of miR-146a-5p in TNBC. The expression level of miR-146a-5p in TNBC tissues and cell lines was initially detected using reverse transcription-quantitative polymerase chain reaction. To predict the target gene of miR-146a-5p, TargetScan software was used and a dual luciferase assay was performed to verify the prediction. Furthermore, in order to explore the role of miR-146a-5p in TNBC, miR-146a-5p was overexpressed in TNBC cells using miR-146a-5p mimics. An MTT assay was performed to detect cell proliferation, and a Transwell assay was conducted to determine cell migration and invasion. Furthermore, western blotting was performed to measure associated protein expression. It was revealed that miR-146a-5p was downregulated in TNBC tissues and cell lines. SOX5 was indicated to be a target gene of miR-146a-5p and was upregulated in TNBC cells. Additionally, miR-146a-5p could inhibit TNBC cell proliferation, migration and invasion, repress the expression of mesenchymal markers $(\mathrm{N}$-cadherin, vimentin and fibronectin) and increase epithelial marker (E-cadherin) expression. Furthermore, SOX5 overexpression eliminated the effects of miR-146a-5p mimics on TNBC cells. In conclusion, the data of the present study indicated that miR-146a-5p inhibits the proliferation and metastasis of TNBC cells by regulating SOX5.
\end{abstract}

Correspondence to: Dr Yufeng Yao, Department of General Surgery, Jiangsu Cancer Hospital, Jiangsu Institute of Cancer Research and Nanjing Medical University Affiliated Cancer Hospital, 42 Baiziting Road, Nanjing, Jiangsu 210009, P.R. China

E-mail: yaoyf2017@163.com

Key words: triple-negative breast cancer, microRNA-146a-5p, SOX5, cell proliferation, metastasis

\section{Introduction}

Breast cancer, which is considered to be the most common type of cancer in women worldwide (1), is divided into four sub-types, including luminal A-like, luminal B-like, human epidermal receptor-2 (HER-2) positive and triple-negative breast cancer (TNBC) (2). TNBC is characterized by the loss of expression of progesterone receptor, estrogen receptor and HER-2 gene expression (3). In total, $15-20 \%$ of breast cancer cases are TNBC and the majority of these are basal-like (4). TNBC, particularly the basal-like type, has higher rates of metastasis and poorer survival rates compared with other breast cancer sub-types (4). Previously, great improvements have been made in the early detection and treatment of breast cancer. However, due to sub-optimal hormonal therapy and a lack of more specific and effective therapeutic targets, TNBC treatment remains a challenge $(5,6)$. Thus, identifying biological markers of TNBC progress is necessary and could provide novel therapeutic strategies for TNBC treatment.

MicroRNAs (miRs) are a class of endogenous, non-coding, single-stranded RNAs that are widely expressed in eukaryotes and are 18-22 nucleotides in length. They serve critical roles in the regulation of gene expression. Furthermore, they are involved in a series of pathological and physiological processes, including tumor proliferation, differentiation and apoptosis (7-9). Furthermore, miRs can transcriptionally inhibit the expression of target genes by binding to the 3'-untranslated region (3'-UTR), acting as oncogenes or tumor inhibitors (10). A growing number of studies have indicated that abnormal expression of miRs is associated with human breast cancer (11-16). Furthermore, mounting evidence indicates that miRs serve key functions in the development of TNBC (17-19). However, the exact molecular mechanism of miRs in TNBC is not yet understood.

miR-146a-5p has been identified as a tumor suppressor in various types of cancer. Zhang et al (20) reported that miR-146a-5p was downregulated in hepatocellular carcinoma and acted as a tumor suppressor. Wang et al (21) revealed that miR-146a-5p promoted esophageal squamous cell carcinoma progression by regulating epithelial-mesenchymal transition (EMT) via targeting Notch2. Furthermore, miR-146a-5p has been confirmed to inhibit non-small cell lung cancer (NSCLC) cell proliferation and cell cycle progression (22). Another study indicated that miR-146a-5p could promote prostate cancer cell 
apoptosis by targeting ROCK1 (23). However, the function of miR-146a-5p in the development of TNBC remains unclear. Therefore, the present study aimed to investigate the function of miR-146a-5p in TNBC and explore its underlying molecular mechanism.

\section{Materials and methods}

Clinical specimens. A total of 20 paired TNBC and adjacent normal breast tissues were identified and collected during biopsies from 20 female patients (age, 27-58 years) with TNBC who were diagnosed by clinical symptoms and imaging examination at the Nanjing Medical University Affiliated Jiangsu Cancer Hospital (Nanjing, China) from January 2015 to December 2016. No patient received preoperative radiotherapy or chemotherapy. All tissue samples were immediately flash-frozen in liquid nitrogen and stored at $-80^{\circ} \mathrm{C}$. The present study was approved by the Human Ethics Committee Review Board at the Nanjing Medical University Affiliated Jiangsu Cancer Hospital (Nanjing, China). Informed consent was provided by every patient.

Cell culture. The non-malignant breast epithelial cell line, MCF-10A, and TNBC cell lines, MDA-MB-231, MDA-MB-468, BT549 and Hs578T, were obtained from the Type Culture Collection of the Chinese Academy of Sciences (Shanghai, China). All cell lines were grown in Dulbecco's modified Eagle's medium (DMEM; HyClone; GE Healthcare Life Sciences, Logan, UT, USA) containing 10\% fetal bovine serum (FBS; Thermo Fisher Scientific, Inc., Waltham, MA, USA) and $1 \%$ penicillin/streptomycin. All cell lines were incubated in a $5 \% \mathrm{CO}_{2}$ incubator at $37^{\circ} \mathrm{C}$ for $\sim 48 \mathrm{~h}$.

Cell transfection. For cell transfection, Hs578T cells were seeded into a 6 -well plate $\left(5 \times 10^{4}\right.$ cells/well) the day prior to transfection. Next, cells were transiently transfected with $50 \mathrm{nM}$ miR-146a-5p mimics (sense, 5'-UGAGAACUGAAU UCCAUGGGUU-3' and antisense, 5'-CCCAUGGAAUUC AGUUCUCAUU-3'), $50 \mathrm{nM}$ negative control miR (sense, 5'-UUCUCCGAACGUGUCACGUdTdT-3' and antisense, 5'-ACGUGACACGUUCGGAGAAdTdT-3'; GenePharma Co., Ltd., Shanghai, China) or miR-146a-5p mimics + SOX5-plamids (GenScript, Piscataway, NJ, USA) using Lipofectamine 2000 transfection reagent (Thermo Fisher Scientific, Inc.), according to the manufacturer's protocol. At $24 \mathrm{~h}$ after cell transfection, the cells were collected and used for the following analyses.

Dual-luciferase reporter assay. TargetScan bioinformatics software (www.targetscan.org/vert_71) was used to predict the target genes of miR-146a-5p, and SOX5 was identified as a potential target of miR-146a-5p. In order to explore whether miR-146a-5p targets the 3'-UTRs of SOX5, vectors termed SOX5-3'-UTR-WT and SOX5-3'-UTR-MUT with wild type and mutated 3'-UTR of SOX5 mRNA, respectively, were constructed. The sense and anti-sense strands of the oligonucleotides of the SOX5-3'-UTR containing the miR-146a-5p binding site were generated, annealed and then sub-cloned into the pMIR-REPORT vector (GeneCopoeia, Inc., Rockville, MD, USA). The negative control was established by sub-cloning scrambled sequences into the same vector. Hs578T cells were seeded into a 24-well plate and then co-transfected with SOX5-3'UTR-WT or SOX5-3'UTR-MUT and miR-146a-5p or its negative control (hsamiR-NC) vector using Lipofectamine 2000 reagent, following the manufacturer's protocol. Following transfection for $48 \mathrm{~h}$ the Dual-Luciferase ${ }^{\circledR}$ Reporter Assay system (Promega Corporation, Madison, WI, USA) was used to determine the luciferase activity according to the manufacturer's protocols. Renilla luciferase activity was normalized to firefly luciferase activity. Every experiment was repeated at least three times.

Reverse transcription-quantitative polymerase chain reaction $(R T-q P C R)$. Total RNA from TNBC tissue samples and Hs578T cells was extracted by TRIzol reagent (Thermo Fisher Scientific, Inc.), according to the manufacturer's protocol. The RevertAid First Strand cDNA synthesis kit (Fermentas; Thermo Fisher Scientific, Inc.) was applied for cDNA generation. qPCR was performed using SYBR-Green qPCR mix (Toyobo Co., Ltd., Osaka, Japan) in a Thermal Cycler Dice Real-Time system III TP950 1 Set (Takara Bio, Inc., Otsu, Japan). GAPDH (for mRNA) or U6 (for miR) acted as the internal controls. The primer sequences used for QPCR were obtained from GenScript and listed in Table I. The thermocycling conditions for qPCR were as follows: $95^{\circ} \mathrm{C}$ for $5 \mathrm{~min}$, followed by 40 cycles of denaturation at $95^{\circ} \mathrm{C}$ for $15 \mathrm{sec}$ and annealing/elongation at $60^{\circ} \mathrm{C}$ for $30 \mathrm{sec}$. The $2^{-\Delta \Delta C q}$ method (24) was used to calculate the relative quantities of each gene. All tests were repeated at least three times.

Western blotting. Total protein was collected from tissues and cells using RIPA lysis buffer (Auragene, Changsha, China). A bicinchoninic acid protein assay kit (Beyotime Institute of Biotechnology, Haimen, China) was applied for protein quantification. Equal amount of protein samples $(25 \mu \mathrm{g})$ were resolved by $10 \%$ SDS-PAGE and then transferred onto a nitrocellulose membrane (EMD Millipore, Billerica, MA, USA). Following blocking with $5 \%$ skimmed milk for $2 \mathrm{~h}$ at room temperature, the membranes were incubated with primary antibodies against SOX5 (cat. no. ab94396), fibronectin (cat. no. ab23750) (both Abcam, Cambridge, UK) Twist1 (cat. no. 46702), $\mathrm{N}$-cadherin (cat. no. 13116) vimentin (cat. no. 5741), E-cadherin (cat. no. 3195) and $\beta$-actin (cat. no. 4970) (all Cell Signaling Technology, Inc., Danvers, MA, USA) at $4^{\circ} \mathrm{C}$ overnight. All primary antibodies were used at a dilution ratio of 1:1,000. The membranes were subsequently incubated with anti-rabbit immunoglobulin $\mathrm{G}$ horseradish peroxidase-linked secondary antibodies (cat. no. 7074; dilution ratio, 1:5,000; Cell Signaling Technology, Inc.) at room temperature for $2 \mathrm{~h}$. For protein band observation, an enhanced chemiluminescence kit (Applygen Technologies, Inc., Beijing, China) and the ChemiDoc XRS+system with Image $\mathrm{Lab}^{\mathrm{TM}}$ software (cat. no. 170-8265; Bio-Rad Laboratories, Inc., Hercules, CA, USA) was used according to the manufacturer's protocol.

MTT assay. At $24 \mathrm{~h}$ after cell transfection, $2.0 \times 10^{3}$ Hs $578 \mathrm{~T}$ cells/well were plated into a 96-well plate (Corning, Inc., Corning, NY, USA) and incubated for $\sim 24 \mathrm{~h}$ at $37^{\circ} \mathrm{C}$ before treatment. Subsequently, $20 \mu \mathrm{l}$ MTT (Sigma-Aldrich; Merck $\mathrm{KGaA}$, Darmstadt, Germany) solution $(5 \mathrm{mg} / \mathrm{ml})$ was added to each well, and then incubated for another $4 \mathrm{~h}$ at $37^{\circ} \mathrm{C}$. 
Table I. Primer sequence for polymerase chain reaction.

\begin{tabular}{|c|c|c|}
\hline Gene name & Direction & Sequence $\left(5^{\prime}-3^{\prime}\right)$ \\
\hline miR-146a-5p & $\mathrm{F}$ & GCGAGGTCAAGTCACTAGTGGT \\
\hline $\operatorname{miR}-146 a-5 p$ & $\mathrm{R}$ & CGAGAAGCTTGCATCACCAGAGAACG \\
\hline SOX5 & $\mathrm{F}$ & CAGCCAGAGTTAGCACAATAGG \\
\hline SOX5 & $\mathrm{R}$ & CTGTTGTTCCCGTCGGAGTT \\
\hline E-cadherin & $\mathrm{F}$ & CGAGAGCTACACGTTCACGG \\
\hline E-cadherin & $\mathrm{R}$ & GGGTGTCGAGGGAAAAATAGG \\
\hline N-cadherin & $\mathrm{F}$ & TTTGATGGAGGTCTCCTAACACC \\
\hline $\mathrm{N}$-cadherin & $\mathrm{R}$ & ACGTTTAACACGTTGGAAATGTG \\
\hline Vimentin & $\mathrm{F}$ & GACGCCATCAACACCGAGTT \\
\hline Vimentin & $\mathrm{R}$ & CTTTGTCGTTGGTTAGCTGGT \\
\hline Fibronectin & $\mathrm{F}$ & GAACCACGCCGAACTACGAT \\
\hline Fibronectin & $\mathrm{R}$ & ATGCGATACATGACCCCTTCA \\
\hline Twist 1 & $\mathrm{~F}$ & GGACAAGCTGAGCAAGATTCA \\
\hline Twist1 & $\mathrm{R}$ & CGGAGAAGGCGTAGCTGAG \\
\hline U6 & $\mathrm{F}$ & CTCGCTTCGGCAGCACA \\
\hline U6 & $\mathrm{R}$ & AACGCTTCACGAATTTGCGT \\
\hline GAPDH & $\mathrm{F}$ & CTTTGGTATCGTGGAAGGACTC \\
\hline GAPDH & $\mathrm{R}$ & GTAGAGGCAGGGATGATGTTCT \\
\hline
\end{tabular}

F, forward; R, reverse; miR, microRNA.

Intracellular formazan crystals were dissolved using dimethyl sulfoxide (Sigma-Aldrich; Merck KGaA). At the end of the test, cell proliferation ability was determined by detecting the absorbance at $490 \mathrm{~nm}$ using a microplate reader.

Transwell assay. To determine cell invasion and migration ability, a Transwell assay was performed $24 \mathrm{~h}$ after cell transfection using Transwell inserts (Corning Incorporated, Corning, NY, USA). For the invasion assay, a membrane coated with Matrigel (BD Biosciences, Franklin Lakes, NJ, USA) was used to construct a matrix barrier. Next, $5 \times 10^{4} \mathrm{Hs} 578 \mathrm{~T}$ cells were seeded into the upper chamber containing $200 \mu \mathrm{l}$ serum-free DMEM medium and $0.1 \%$ bovine serum albumin (Thermo Fisher Scientific, Inc.). In total, $500 \mu 1$ medium supplemented with $15 \%$ FBS was added into the lower chamber. For the migration assay, Hs578T cells were incubated for $24 \mathrm{~h}$ at $37^{\circ} \mathrm{C}$, and for the invasion assay, the cells were incubated for $48 \mathrm{~h}$ at $37^{\circ} \mathrm{C}$. Cells on the upper membranes were wiped away, and the migrated or invasive cells on the lower membranes were firstly fixed with $95 \%$ ethyl alcohol for $15 \mathrm{~min}$ at room temperature and then stained with $0.1 \%$ crystal violet for $15 \mathrm{~min}$ at $37^{\circ} \mathrm{C}$. At the end of the experiment, the cells were counted under an inverted light microscope (Olympus Corporation, Tokyo, Japan) using Image J software version $1.48 \mathrm{u}$ (National Institutes of Health, Bethesda, MD, USA).

Statistical analysis. Statistical analysis was applied using SPSS version 21.0 (IBM Corp., Armonk, NY, USA). Each experiment was repeated in triplicate. Data are presented as the mean \pm standard deviation. Comparisons between two groups were performed using Student's t-test. Comparisons between multiple groups were performed using one-way analysis of variance followed by Tukey's post hoc test. $\mathrm{P}<0.05$ was considered to indicate a statistically significant difference.

\section{Results}

miR-146a-5p is downregulated in TNBC specimens and cell lines. The expression level of miR-146a-5p was detected in TNBC specimens and the TNBC cell lines, MDA-MB-231, MDA-MB-468, BT549 and Hs578T, by RT-qPCR. As depicted in Fig. 1, compared with the normal control, the level of miR-146a-5p was significantly decreased in TNBC tissues and the TNBC cell lines, MDA-MB-231, MDA-MB-468, BT549 and Hs578T. The data indicated that miR-146a-5p may be involved in TNBC progression. Since the TNBC cell line Hs578T demonstrated a more marked decrease in miR-146a-5p expression compared with the control, Hs578T cells were selected for further experiments.

miR-146a-5p targets SOX5. To investigate the mechanisms of the function that miR-146a-5p serves in TNBC, the target gene of miR-146a-5p was predicted using TargetScan, and a dual luciferase assay was performed to verify the prediction. As predicted, it was revealed that miR-146a-5p directly targets SOX5 (Fig. 2).

Furthermore, it was revealed that SOX5 protein was expressed at notably higher levels in the TNBC cell line, Hs578T, compared with MCF-10A cells (Fig. 3A). Compared with MCF-10A cells, the mRNA level of SOX5 was significantly increased in Hs578T cells (Fig. 3B). Additionally, it was revealed that miR-146a-5p negatively regulated the protein and mRNA expression of SOX5 in Hs578T cells. miR-146a-5p mimics markedly decreased the SOX5 protein expression, 
A

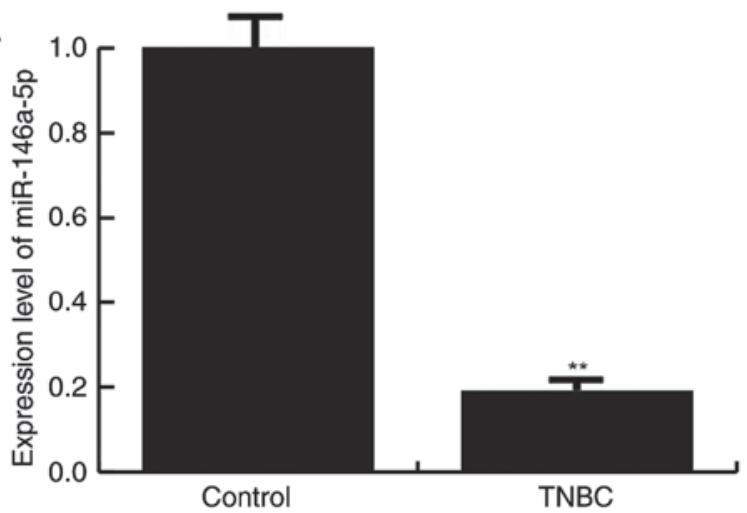

B

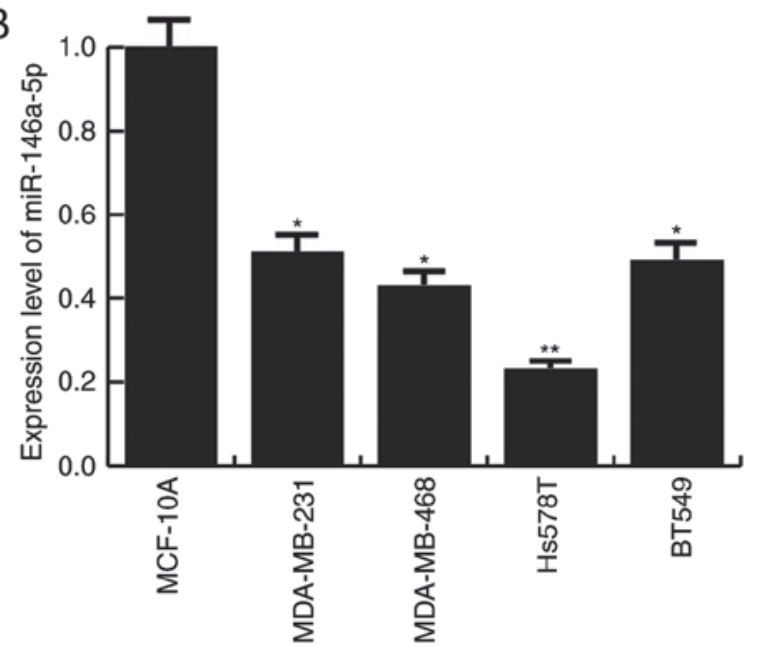

Figure 1. Expression level of miR-146a-5p in TNBC. Relative miR-146a-5p expression in (A) TNBC tissues and (B) cell lines was determined by reverse transcription-quantitative polymerase chain reaction. Data are expressed as the mean \pm standard deviation. ${ }^{*} \mathrm{P}<0.05$ and ${ }^{* *} \mathrm{P}<0.01 \mathrm{vs}$. control. TNBC, triple-negative breast cancer; miR, microRNA.

\section{A}
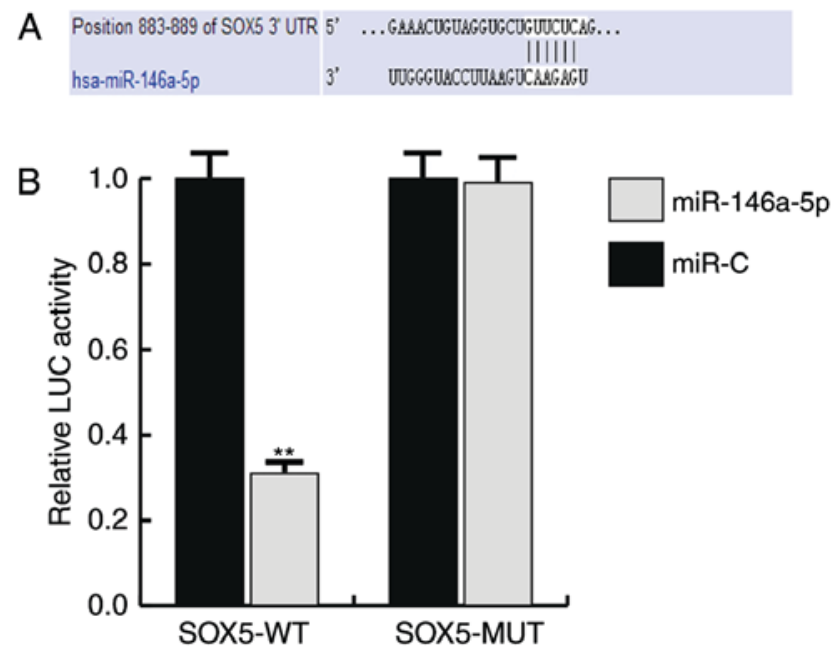

Figure 2. SOX5 is a target gene of miR-146a-5p. (A) TargetScan software was used to predict the interaction between miR-146a-5p and the 3'-UTR of SOX5. (B) Luciferase activity was assessed by performing a dual luciferase assay. MUT indicates the SOX5 3'-UTR with a mutation in the miR-146a-5p binding site. Data are presented as the mean \pm standard deviation. ${ }^{* *} \mathrm{P}<0.01$ vs. control. UTR, untranslated region; LUC, luciferase; WT, wild type; miR, microRNA.

and this decrease was reversed by SOX5-plasmids (Fig. 3C). It was also observed that the mRNA level of SOX5 significantly decreased in miR-146a-5p mimics treated Hs578T cells and this reduction was significantly reversed by SOX5-plasmids (Fig. 3D).

miR-146a-5p inhibits TNBC cell proliferation. To investigate the effect of miR-146a-5p on TNBC cell proliferation, an MTT assay was performed. Hs578T cells were transfected with miR-146a-5p mimics, its negative control or miR-146a-5p mimics + SOX5-plamids, and the MTT assay was performed $24 \mathrm{~h}$ after cell transfection. The results indicated that compared with the controls, the Hs578T cell proliferation ability was significantly decreased in the cells transfected with miR-146a-5p mimics, and SOX5-plamids significantly reverse this effect (Fig. 4).
miR-146a-5p decreases migration and invasion capacities of TNBC cells. After $24 \mathrm{~h}$ of cell transfection, Transwell assays were performed to determine cell migration and invasion rates. It was revealed that miR-146a-5p mimics significantly inhibited Hs578T cell migration and invasion compared with the controls, and this effect could be significantly reversed by SOX5 overexpression (Fig. 5).

miR-146a-5p inhibits EMT. To determine the effect of miR-146a-5p on TNBC cell EMT, the expression levels of mesenchymal markers ( $\mathrm{N}$-cadherin, vimentin and fibronectin) and an epithelial marker (E-cadherin) were detected by RT-qPCR and western blotting. The results revealed that miR-146a-5p mimics significantly reduced the mRNA expression of $\mathrm{N}$-cadherin, vimentin and fibronectin compared with the control, but significantly enhanced the mRNA level of E-cadherin (Fig. 6A-E). Similar results were obtained from western blot analysis (Fig. 6F). These effects could be significantly reversed by SOX 5 overexpression. A previous study revealed that SOX5 could induce EMT by regulating Twist1 expression (25). In the present study, the data indicated that miR-146a-5p mimics significantly decreased Twist1 expression compared with the controls, and this decrease could be significantly reversed by SOX5 overexpression (Fig. 6).

\section{Discussion}

TNBC has a strong potential to metastasize, and the majority of patients succumb to the disease due to distant metastasis (26). Recently, EMT has become the focal point of research into the metastatic process $(27,28)$. Due to a lack of reliable markers and effective therapeutic targets, TNBC has increasingly attracted the attention of researchers.

Abnormal expression of miRNAs is known to be involved in the development of a variety of types of cancer, and studies have revealed potential of miRNAs as biomarkers for diagnosis and prognosis $(29,30)$. Recently, a number of studies have indicated that miRNAs serve critical roles in the development of TNBC. Jia et al (31) reported that miR-490-3p could suppress the growth 
A

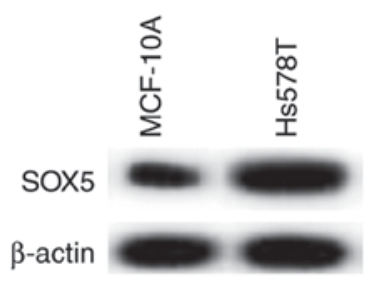

C

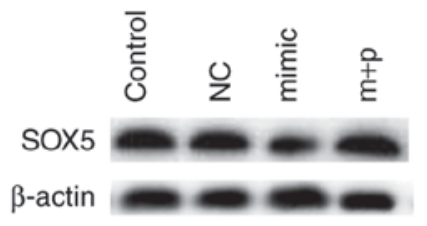

B
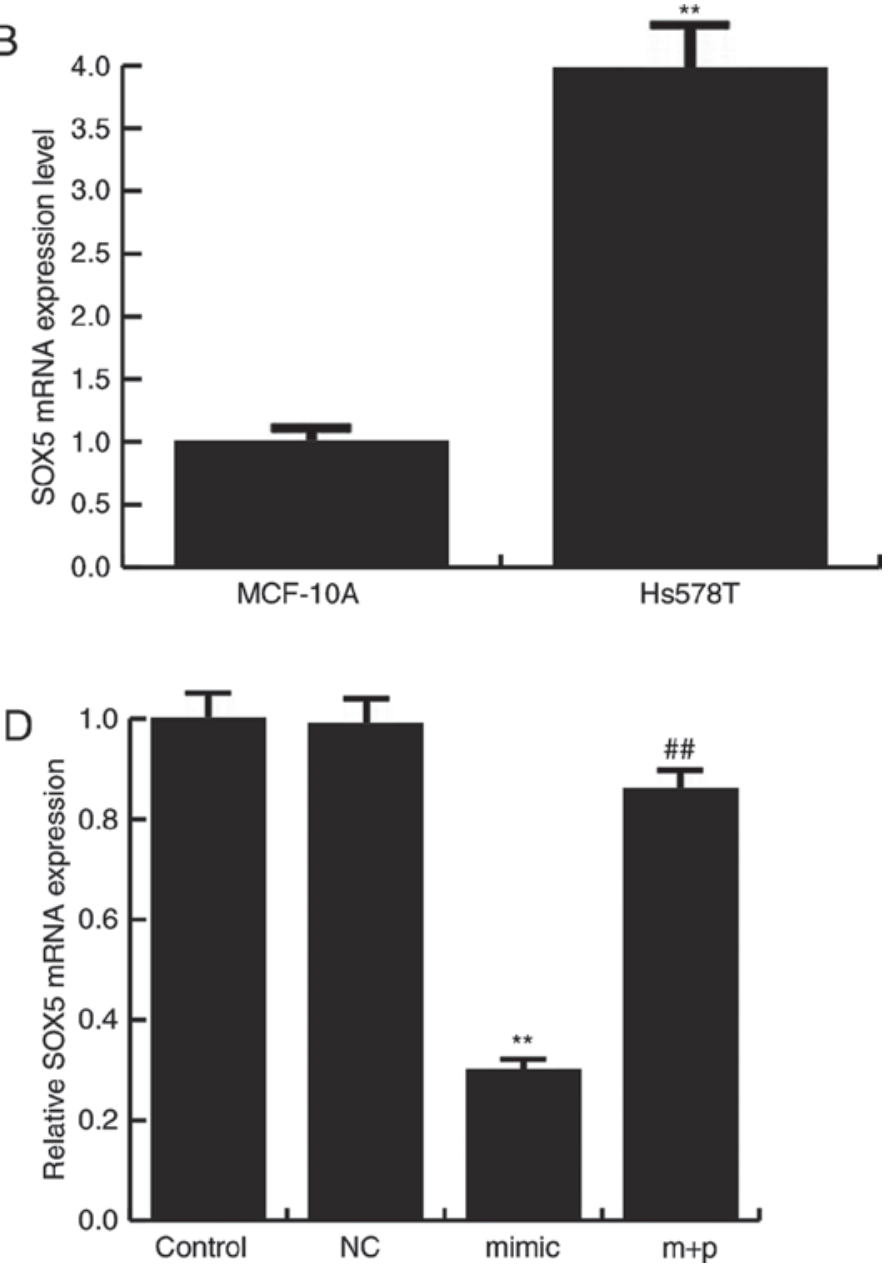

Figure 3. SOX5 expression in Hs578T cells. The expression level of SOX5 was detected by western blotting and reverse transcription-quantitative polymerase chain reaction. (A) Protein and (B) mRNA level of SOX5 in MCF-10A and Hs578T cells. (C) Protein and (D) mRNA level of SOX5 in Hs578T cells in different groups. Control, Hs578T cells without any treatment. NC, Hs578T cells transfected with the negative control of miR-146a-5p mimics. Mimic, Hs578T cells transfected with miR-146a-5p mimics. m+p, Hs578T cells co-transfected with miR-146a-5p mimics and SOX5 plasmids. All data are presented as the mean \pm standard deviation. ${ }^{* *} \mathrm{P}<0.01$ vs. control; ${ }^{\# \#} \mathrm{P}<0.01$ vs. mimic. miR, microRNA.

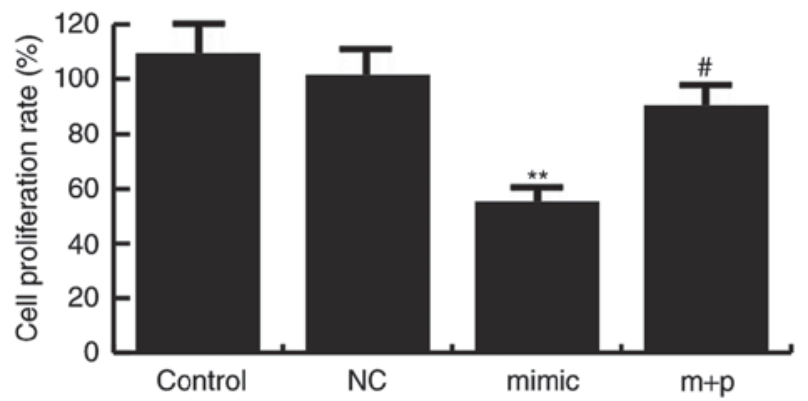

Figure 4. Effects of miR-146a-5p on Hs578T cell proliferation. At $24 \mathrm{~h}$ after cell transfection, an MTT assay was performed to detect the effect of miR-216b-3p on Hs578T cell proliferation. Control: Hs578T cells without any treatment. NC: Hs578T cells transfected with the negative control of miR-146a-5p mimics. Mimic: Hs578T cells transfected with miR-146a-5p mimics. m+p: Hs578T cells co-transfected with miR-146a-5p mimics and SOX 5 plasmids. Data are presented as the mean \pm standard deviation. ${ }^{* *} \mathrm{P}<0.01$ vs. control; ${ }^{*} \mathrm{P}<0.05$ vs. mimic. miR, microRNA.

and invasion of TNBC by inhibiting tankyrase-2 expression. Choi et al (32) indicated that miR-141/200c was involved in TNBC migration and invasion via activating the focal adhesion kinase and phosphoinositide 3-kinase/AKT signaling pathways. miRNA-454 was revealed to be associated with poor prognosis in TNBC (17) and miRNA-200b could suppress TNBC metastasis by regulating protein kinase $\mathrm{C} \alpha$ (19). Furthermore, miR-211-5p served a tumor suppressor role in TNBC progression by targeting SETBP1 (33) and miRNA-21 could promote TNBC cell proliferation and invasion by regulating phosphatase and tensin homolog (34).

miR-146a-5p functions as a tumor suppressor in various types of cancer, including hepatocellular carcinoma, esophageal squamous cell carcinoma, NSCLC and prostate cancer (20-23). However, the role of miR-146a-5p in the development of TNBC remains unclear. The present study investigated the expression and role of miR-146a-5p in TNBC, and it was revealed that miR-146a-5p was downregulated in TNBC tissues and cell lines (MDA-MB-231 MDA-MB-468, BT549 and Hs578T). SOX5 was identified as a target gene of miR-146a-5p and was overexpressed in TNBC cells. As miR-146a-5p was more evidently decreased in the TNBC cell line Hs578T, the Hs578T cell line was selected to perform further investigations. Additionally, the present study demonstrated that miR-146a-5p could prevent TNBC Hs578T cell proliferation, migration, invasion and EMT.

To the best of our knowledge the present study was the first to demonstrate that miR-146a-5p was downregulated 
A

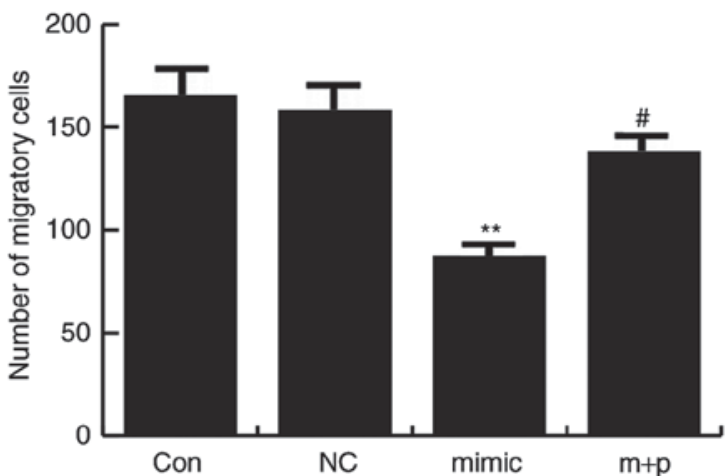

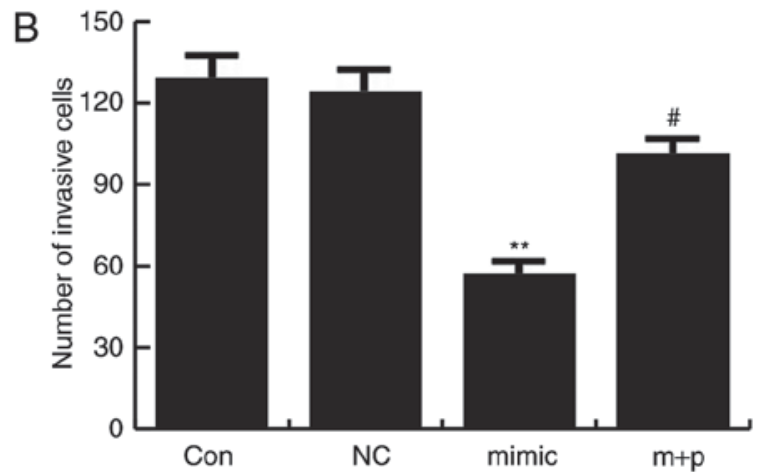

Figure 5. Effects of miR-146a-5p on Hs578T cell migration and invasion. At $24 \mathrm{~h}$ after cell transfection, Transwell assays were performed to detect the effect of miR-216b-3p on Hs578T cell (A) migration and (B) invasion. Control, Hs578T cells without any treatment. NC, Hs578T cells transfected with the negative control of miR-146a-5p mimics. Mimic, Hs578T cells transfected with miR-146a-5p mimics. m+p, Hs578T cells co-transfected with miR-146a-5p mimics and SOX5 plasmids. Data are presented as the mean \pm standard deviation. ${ }^{* *} \mathrm{P}<0.01$ vs. control; ${ }^{\#} \mathrm{P}<0.05$ vs. mimic. miR, microRNA.

A

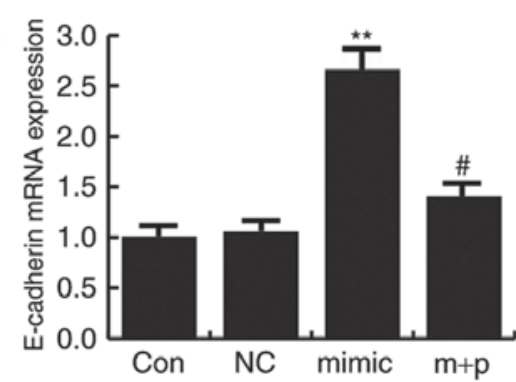

D

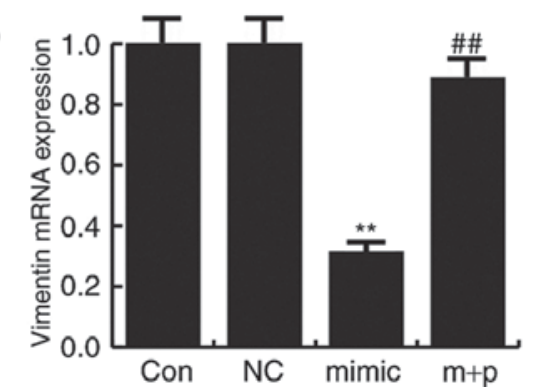

B

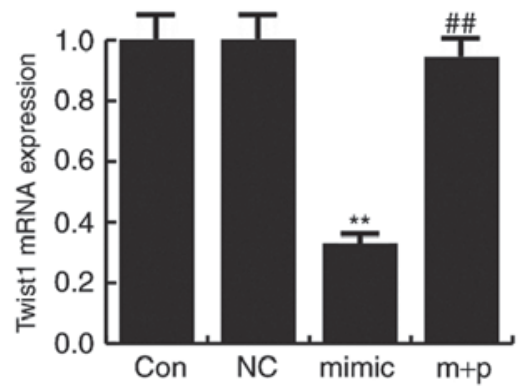

E

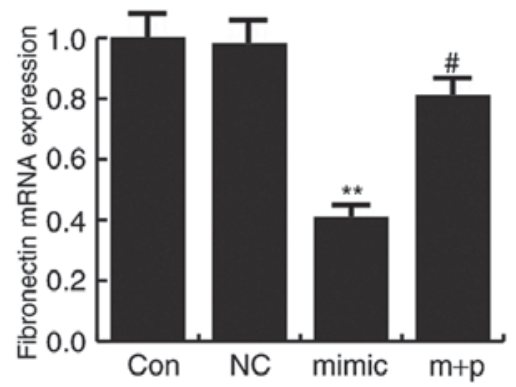

C

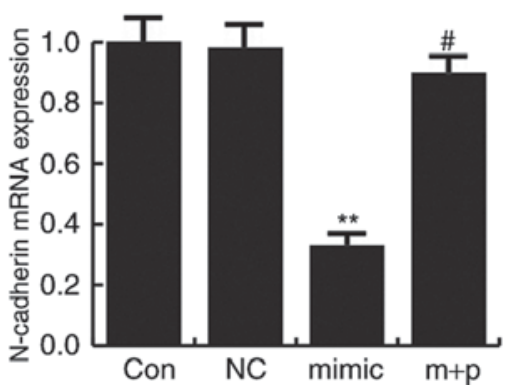

F

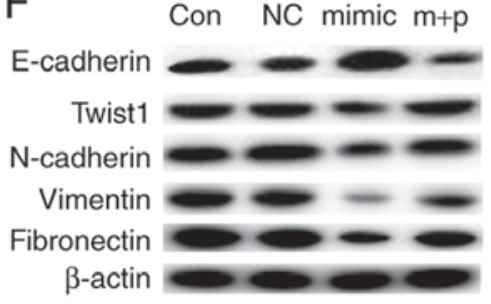

Figure 6. Effects of miR-146a-5p on the expression level of epithelial-mesenchymal transition markers in Hs578T cells. At 24 h after cell transfection, the expression level of Twist1, N-cadherin, vimentin, fibronectin and E-cadherin was determined by (A) western blotting and (B-F) reverse transcription-quantitative polymerase chain reaction. Control, Hs578T cells without any treatment. NC, Hs578T cells transfected with the negative control of miR-146a-5p mimics. Mimic, Hs578T cells transfected with miR-146a-5p mimics. m+p, Hs578T cells co-transfected with miR-146a-5p mimics and SOX5 plasmids. Data are presented as the mean \pm standard deviation. ${ }^{* *} \mathrm{P}<0.01$ vs. control; ${ }^{\#} \mathrm{P}<0.05$ and ${ }^{\# \#} \mathrm{P}<0.01$ vs. mimic.

in TNBC tissues and cells, and miR-146a-5p could repress TNBC cell proliferation, migration, invasion and EMT by targeting SOX5. Furthermore, miR-146a-5p and SOX5 may potentially be used as novel targets for TNBC treatment, and the current study provides basis for exploring novel therapies for the clinical treatment of TNBC.

\section{Acknowledgements}

The present study was supported by Jiangsu Provincial Medical Youth Talent and the Project of Invigorating Health Care through Science, Technology and Education (grant no. QNRC2016661).

\section{Competing interests}

The authors declare that they have no competing interests.

\section{References}

1. Wang H, Tan G, Dong L, Cheng L, Li K, Wang Z and Luo H: Circulating MiR-125b as a marker predicting chemoresistance in breast cancer. PLoS One 7: e34210, 2012.

2. Coates AS, Winer EP, Goldhirsch A, Gelber RD, Gnant M, Piccart-Gebhart M, Thürlimann B and Senn HJ; Panel Members: Tailoring therapies-improving the management of early breast cancer: St Gallen international expert consensus on the primary therapy of early breast cancer 2015. Ann Oncol 26: 1533-1546, 2015.

3. Dent R, Trudeau M, Pritchard KI, Hanna WM, Kahn HK, Sawka CA, Lickley LA, Rawlinson E, Sun P and Narod SA: Triple-negative breast cancer: Clinical features and patterns of recurrence. Clin Cancer Res 13: 4429-4434, 2007.

4. Prat A, Parker JS, Karginova O, Fan C, Livasy C, Herschkowitz JI, He X and Perou CM: Phenotypic and molecular characterization of the claudin-low intrinsic subtype of breast cancer. Breast Cancer Res 12: R68, 2010.

5. Liu Y, Zhu P, Wang Y, Wei Z, Tao L, Zhu Z, Sheng X, Wang S, Ruan J, Liu Z, et al: Antimetastatic therapies of the polysulfide diallyl trisulfide against triple-negative breast cancer (TNBC) via suppressing MMP2/9 by blocking NF-kB and ERK/MAPK signaling pathways. PLoS One 10: e0123781, 2015. 
6. Gucalp A and Traina TA: Triple-negative breast cancer: Role of the androgen receptor. Cancer J 16: 62-65, 2010.

7. Krol J, Loedige I and Filipowicz W: The widespread regulation of microRNA biogenesis, function and decay. Nat Rev Genet 11 597-610, 2010.

8. Winter J, Jung S, Keller S, Gregory RI and Diederichs S: Many roads to maturity: microRNA biogenesis pathways and their regulation. Nat Cell Biol 11: 228-234, 2009.

9. Sandhu S and Garzon R: Potential applications of microRNAs in cancer diagnosis, prognosis, and treatment. Semin Oncol 38 781-787, 2011

10. Garzon R, Marcucci G and Croce CM: Targeting microRNAs in cancer: Rationale, strategies and challenges. Nat Rev Drug Discov 9: 775-789, 2010.

11. Bertoli G, Cava C and Castiglioni I: MicroRNAs: New biomarkers for diagnosis, prognosis, therapy prediction and therapeutic tools for breast cancer. Theranostics 5: 1122-1143, 2015.

12. Yoo B, Kavishwar A, Ross A, Wang P, Tabassum DP, Polyak K, Barteneva N,Petkova V,Pantazopoulos P, Tena A, et al: Combining miR-10b-targeted nanotherapy with low-dose doxorubicin elicits durable regressions of metastatic breast cancer. Cancer Res 75 4407-4415, 2015.

13. De Leeneer $\mathrm{K}$ and Claes $\mathrm{K}$ : Non coding RNA molecules as potential biomarkers in breast cancer. Adv Exp Med Biol 867: 263-275, 2015

14. Yuan Y, Anbalagan D, Lee LH, Samy RP, Shanmugam MK, Kumar AP, Sethi G, Lobie PE and Lim LH: ANXA1 inhibits miRNA-196a in a negative feedback loop through NF- $\mathrm{B}$ and c-Myc to reduce breast cancer proliferation. Oncotarget 7 27007-27020, 2016.

15. Yoo JO, Kwak SY, An HJ, Bae IH, Park MJ and Han YH: miR-181b-3p promotes epithelial-mesenchymal transition in breast cancer cells through Snail stabilization by directly targeting YWHAG. Biochim Biophys Acta 1863: 1601-1611, 2016.

16. Hemmatzadeh M, Mohammadi H, Jadidi-Niaragh F, Asghari F and Yousefi M: The role of oncomirs in the pathogenesis and treatment of breast cancer. Biomed Pharmacother 78: 129-139, 2016.

17. Cao ZG, Li JJ, Yao L, Huang YN, Liu YR, Hu X, Song CG and Shao ZM: High expression of microRNA-454 is associated with poor prognosis in triple-negative breast cancer. Oncotarget 7 : 64900-64909, 2016

18. Tang L, Wei D and Yan F: MicroRNA-145 functions as a tumor suppressor by targeting matrix metalloproteinase 11 and Rab GTPase family 27a in triple-negative breast cancer. Cancer Gene Ther 23: 258-265, 2016.

19. Humphries B, Wang Z, Oom AL, Fisher T, Tan D, Cui Y, Jiang Y and Yang C: MicroRNA-200b targets protein kinase Ca and suppresses triple-negative breast cancer metastasis. Carcinogenesis 35: 2254-2263, 2014.

20. Zhang X, Ye ZH, Liang HW, Ren FH, Li P, Dang YW and Chen G: Down-regulation of miR-146a-5p and its potential targets in hepatocellular carcinoma validated by a TCGA- and GEO-based study. FEBS Open Bio 7: 504-521, 2017.

21. Wang $C$, Zhang W, Zhang L, Chen X, Liu F, Zhang J, Guan S, Sun Y, Chen P, Wang D, et al: miR-146a-5p mediates epithelialmesenchymal transition of oesophageal squamous cell carcinoma via targeting Notch2. Br J Cancer 115: 1548-1554, 2016.
22. Li YL, Wang J, Zhang CY, Shen YQ, Wang HM, Ding L, Gu YC, Lou JT, Zhao XT, Ma ZL and Jin YX: MiR-146a-5p inhibits cell proliferation and cell cycle progression in NSCLC cell lines by targeting CCND1 and CCND2. Oncotarget 7: 59287-59298, 2016.

23. Xu B, Huang Y, Niu X, Tao T, Jiang L, Tong N, Chen S, Liu N, Zhu W and Chen M: Hsa-miR-146a-5p modulates androgenindependent prostate cancer cells apoptosis by targeting ROCK1. Prostate 75: 1896-1903, 2015.

24. Livak KJ and Schmittgen TD: Analysis of relative gene expression data using real-time quantitative PCR and the 2(-Delta Delta C(T)) method. Methods 25: 402-408, 2001.

25. Pei XH, Lv XQ and Li HX: Sox5 induces epithelial to mesenchymal transition by transactivation of Twist1. Biochem Biophys Res Commun 446: 322-327, 2014.

26. Tseng LM, Hsu NC, Chen SC, Lu YS, Lin CH, Chang DY, Li H, Lin YC, Chang HK, Chao TC, et al: Distant metastasis in triple-negative breast cancer. Neoplasma 60: 290-294, 2013.

27. Han Y, Zhang L, Wang W, Li J and Song M: Livin promotes the progression and metastasis of breast cancer through the regulation of epithelial-mesenchymal transition via the p38/GSK3 $\beta$ pathway. Oncol Rep 38: 3574-3582, 2017.

28. Okita Y, Kimura M, Xie R, Chen C, Shen LT, Kojima Y, Suzuki H, Muratani M, Saitoh M, Semba K, et al: The transcription factor MAFK induces EMT and malignant progression of triple-negative breast cancer cells through its target GPNMB. Sci Signal 10: pii: eaak9397, 2017.

29. van Schooneveld E, Wildiers H, Vergote I, Vermeulen PB, Dirix LY and Van Laere SJ: Dysregulation of microRNAs in breast cancer and their potential role as prognostic and predictive biomarkers in patient management. Breast Cancer Res 17: 21, 2015.

30. McGuire A, Brown JA and Kerin MJ: Metastatic breast cancer: The potential of miRNA for diagnosis and treatment monitoring. Cancer Metastasis Rev 34: 145-155, 2015.

31. Jia Z, Liu Y, Gao Q, Han Y, Zhang G, Xu S, Cheng K and Zou W: miR-490-3p inhibits the growth and invasiveness in triple-negative breast cancer by repressing the expression of TNKS2. Gene 593: 41-47, 2016.

32. Choi SK, Kim HS, Jin T, Hwang EH, Jung M and Moon WK: Overexpression of the miR-141/200c cluster promotes the migratory and invasive ability of triple-negative breast cancer cells through the activation of the FAK and PI3K/AKT signaling pathways by secreting VEGF-A. BMC Cancer 16: 570, 2016.

33. Chen LL, Zhang ZJ, Yi ZB and Li JJ: MicroRNA-211-5p suppresses tumour cell proliferation, invasion, migration and metastasis in triple-negative breast cancer by directly targeting SETBP1. Br J Cancer 117: 78-88, 2017.

34. Fang H, Xie J, Zhang M, Zhao Z, Wan Y and Yao Y: miRNA-2 promotes proliferation and invasion of triple-negative breast cancer cells through targeting PTEN. Am J Transl Res 9: 953-961, 2017. 